\title{
Properties Of Steel Fiber Reinforcement Concrete With Different Characteristic Of Steel Fiber
}

\author{
Shahiron Shahidan ${ }^{1}$ a, Mustaqqim Abdul Rahim $^{2 b}$, NikSuharlizaNikZol $^{2 c}$ \\ Muhammad Azizi Azizan ${ }^{2}$, Isham Ismail ${ }^{1 \mathrm{e}}$ \\ ${ }^{1}$ Faculty of Civil and Enviromental Engineering, UniversitiTun Hussein Onn, 86400, BatuPahat, \\ Johor, Malaysia. \\ ${ }^{2}$ Civil Engineering Department, School of Environmental Engineering, Universiti Malaysia Perlis, \\ 02600 Arau, Perlis, Malaysia. \\ Email: ${ }^{a}$ shahiron@uthm.edu.my ${ }^{b}$ mustaqqim@unimap.edu.my \\ cniksuharliza_nikzol@yahoo.com.my daziziazizan@unimap.edu.my ${ }^{\mathrm{e} i s h a m @ u t h m . e d u . m y ~}$
}

\begin{abstract}
Keywords: Steel Fiber, Volume Friction, Length of Steel Fiber, Fresh Concrete, Compressive Strength Test.
\end{abstract}

\begin{abstract}
Currently in concrete technology a lot of materials were introduced to improve the quality and properties of concrete. Additional materials include the use of steel fibers into the concrete mix. With the used of steel fibers, it can enhance the strength of the concrete. In this research, two parameters will be investigated which is the volume friction of the steel fiber and the length of the steel fiber. End-hooked steel fiber with the length of $33 \mathrm{~mm}$ and $50 \mathrm{~mm}$ and the percentage of steel fiber $0.5 \%, 1.0 \%$ and $1.5 \%$ used in this research. The size of the mold used is $100 \mathrm{~mm} \times 100 \mathrm{~mm} \times 100 \mathrm{~mm}$. The characteristics during the fresh concrete were also investigated by conducting the slump test, compaction test and vebe test. All the samples has been cured in the water for $7^{\text {th }}, 14^{\text {th }}$ and $28^{\text {th }}$ days for the compressive strength test. Based on result, it was concluded that the optimum percentage of steel fiber in this report was $1.0 \%$ for the end-hooked steel fiber with $33 \mathrm{~mm}$ length which provided the highest compressive strength at 28 days.
\end{abstract}

\section{Introduction}

Concrete is the most common construction material in the industry. The tensile strength of concrete is usually only about one tenth of its compressive strength and relatively brittle [1].Usually the normal concrete is reinforced with steel reinforcing bars. For most application, with small and randomly distributed fibers it is becoming increasingly popular to reinforce the concrete. In the past 50 years, fiber reinforced concrete (FRC) has been shown not only give a better resistance to high strain rate loading compared to conventional concrete but also provide better control of plastic shrinkage and crack spreads. Thus, the FRC more commonly used to resist impact or explosive loads in structures designed [2].

The fiber was used in concrete to increase the tensile strength of concrete. The fiber can help to maintain the structural integrity and cohesiveness in the material. It also can help to provide crack resistance and crack control, improve the post-cracking and others. About 40 years ago the design and research of the steel fiber reinforced concrete (SFRC) start to increase and after that various types of steel fiber have been developed. The steel fiber was produced in the different of shape, size and surface structure. The steel fiber that was produced has different mechanical properties such as tensile strength, grade of mechanical anchorage and capability of stress distribution and absorption. Thus the concrete properties have the different influence [3].The objectives of this research is to determine the compression strength of the steel fiber reinforced concrete and to compare the effect of different characteristic of steel fiber reinforced concrete as well as to assess the workability of the fresh concrete with the different percentage of steel fiber. 


\section{Materialsand Methods}

The type steel fiber used was hooked and steel fiber. Different characteristic which is $33 \mathrm{~mm}$ and 50 $\mathrm{mm}$ long of steel fiber. The steel fiber obtained from MaccaferriSdn Bhd. The mix proportion for the steel fiber are $0.5 \%, 1.0 \%$ and $1.5 \%$ and calculate based on the volume friction. The size of mould was $100 \mathrm{~mm} \times 100 \mathrm{~mm} \times 100 \mathrm{~mm}$. Test on fresh concrete such as slump test, compaction factor test, Vebe test. This test was to measure the workability of the fresh concrete. The concrete slump test was according to BS 1881 : Part 102 : 1983 [4]. Compaction factor test was done according to BS : $1191: 1959$ [5]. Vebe test was done according to the standard BS EN 12350-3, 2009 [6]. The curing was an important process to prevent the concrete specimens from losing their moisture while they are gaining their required strength. It was according to BS 1881 Park 112 : 1983 [7]. All concrete specimens will cure in water at room temperature for $7^{\text {th }}, 14^{\text {th }}$ and $28^{\text {th }}$ days. The tests for compressive strength were done on $100 \mathrm{~mm}$ x $100 \mathrm{~mm}$ x $100 \mathrm{~mm}$ cubes in accordance to the standard MS EN 12390-3:2012 [8]. Compressive strength is defined as the maximum resistant of the concrete cube to axial loading.

\section{Resultsand Discussions}

\section{Slump test}

From the Figure 1, it shows that the slump test has low workability when the percentage of steel fiber was increase. With $0.5 \%$ steel fiber the result shows that the $33 \mathrm{~mm}$ length of steel fiber has higher workability which is $97 \mathrm{~mm}$ and the $50 \mathrm{~mm}$ length of steel fiber only was $90 \mathrm{~mm}$. The short steel fibers have high workability than the long steel fiber. A short length of steel fiber will fill up the void and the concrete will compacted. If the workability was high that means the slump test result will be increased.From the table 1, the degree of workability for the in this experiment was classified as medium that ranging from 50 to $100 \mathrm{~mm}$.

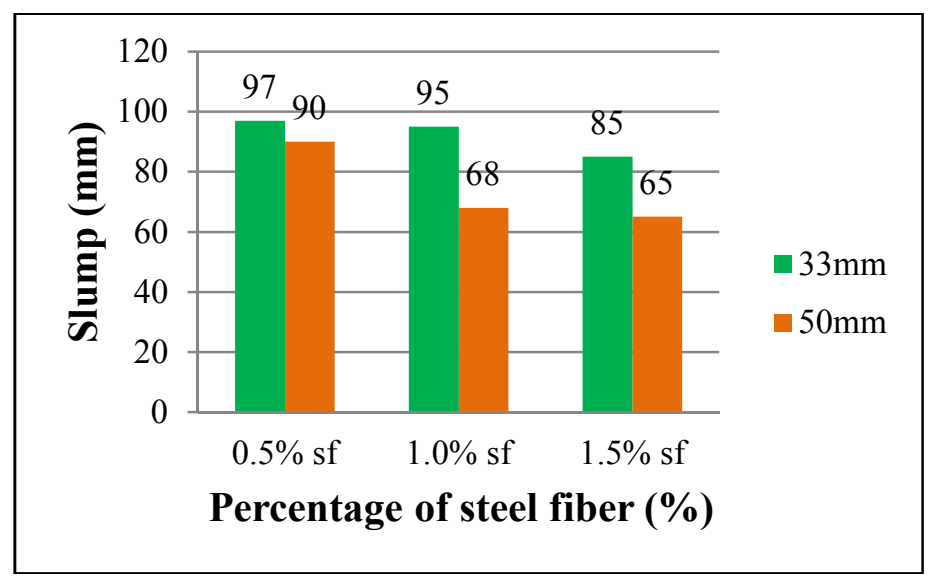

Figure 1 : Slump test result $(\mathrm{mm})$ versus percentage of steel fiber (\%).

Table 1 : The standard of slump test result.

\begin{tabular}{|l|l|}
\hline Degree of workability & Slump (mm) \\
\hline Very low & $0-25 \mathrm{~mm}$ \\
\hline Low & $25-50 \mathrm{~mm}$ \\
\hline Medium & $50-100 \mathrm{~mm}$ \\
\hline High & $100-175 \mathrm{~mm}$ \\
\hline Very high & collapsed \\
\hline
\end{tabular}




\section{Compaction factor test}

The result for compaction test was shown in Figure 2. The higher compaction factor was 0.92 for 33 $\mathrm{mm}$ length of steel fiber at $0.5 \%$ compared to $55 \mathrm{~mm}$ length of steel fiber only 0.90 . When the percentage of steel fiber was increased, the value of compaction test result was decreased. The result was slowly decreased by the increasingly percentage of the steel fiber. The others result for $33 \mathrm{~mm}$ and $50 \mathrm{~mm}$ length of steel fiber is suitable compaction factor because it is between 0.85 to 0.92 and it having medium and low workability as show in Table 2.

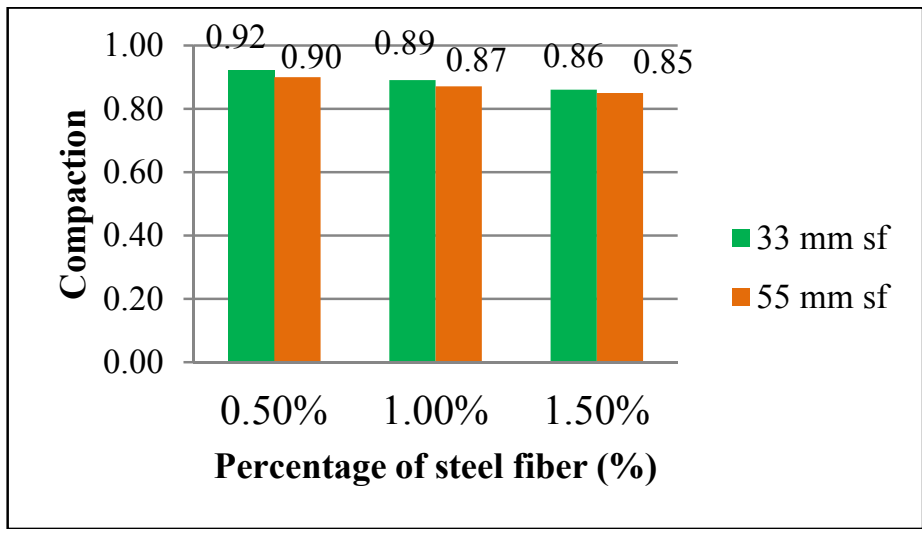

Figure 2 : Compaction factor versus percentage of steel fiber (\%).

Table 2: The standard of compaction test result.

\begin{tabular}{|l|l|}
\hline Range & Workability \\
\hline$<0.75$ & Very low \\
\hline $0.75-0.85$ & Low \\
\hline $0.85-0.92$ & Medium \\
\hline $0.92-0.95$ & High \\
\hline
\end{tabular}

\section{Vebe test}

Figure 3 show the result of Vebe test. The length of $33 \mathrm{~mm}$ steel fiber has shorter Vebe time compared than the $50 \mathrm{~mm}$ length of steel fiber. When the amount of steel fiber and length of steel fiber was increase, the Vebe time also was increased. Its means the workability are high. The workability was effect due to length of steel fiber. Concrete are insensitive when using longer steel fiber in the concrete. The $50 \mathrm{~mm}$ lengthwith $1.5 \%$ of steel fiber has the highest Vebe time among all other mixes.

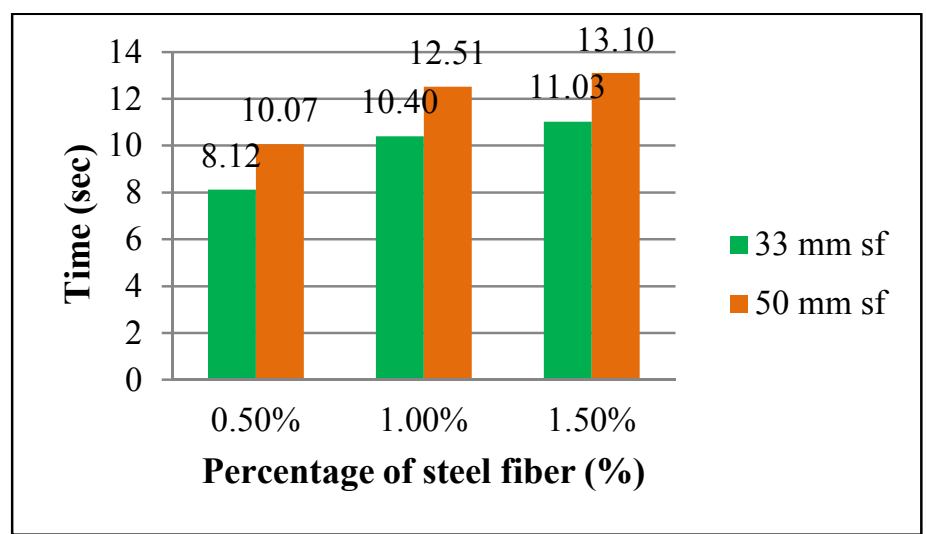

Figure 3 :Vebe time (sec) versus percentage of steel fiber (\%). 


\section{Compressive strength test}

4.1 Compressive strength for $0.5 \%$ of steel fiber.

The $33 \mathrm{~mm}$ length of steel fiber was stronger compared to $50 \mathrm{~mm}$ length of steel fiber in term of compressive strength. The higher compressive strength was $34.48 \mathrm{MPa}$ at the $28^{\text {th }}$ days for the 33 $\mathrm{mm}$ length of steel fiber. This might be due because the short steel fiber was easy to fill up the void and the concrete was compacted compared with long steel fiber.

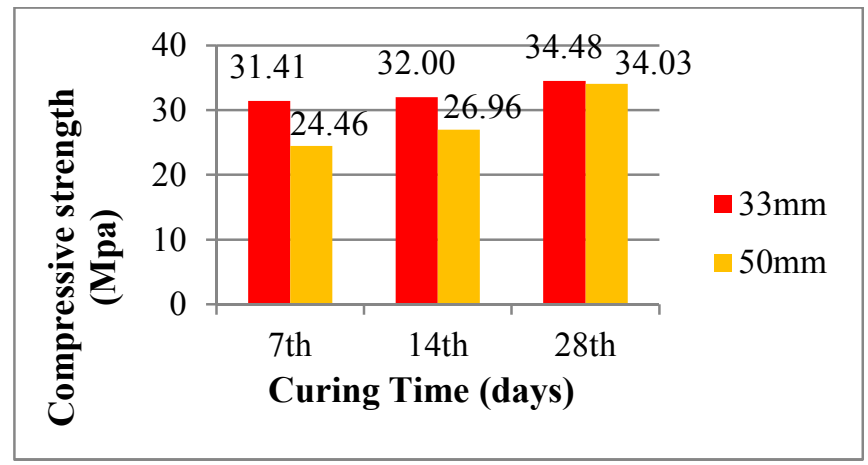

Figure 4 : Compressive strength for $0.5 \%$ of steel fiber.

4.2 Compressive strength for $1.0 \%$ of steel fiber.

The same result was obtained for the $1.0 \%$ of steel fiber. The higher compressive strength was 46.04 Mpa at the $28^{\text {th }}$ days from $33 \mathrm{~mm}$ length of steel fiber.

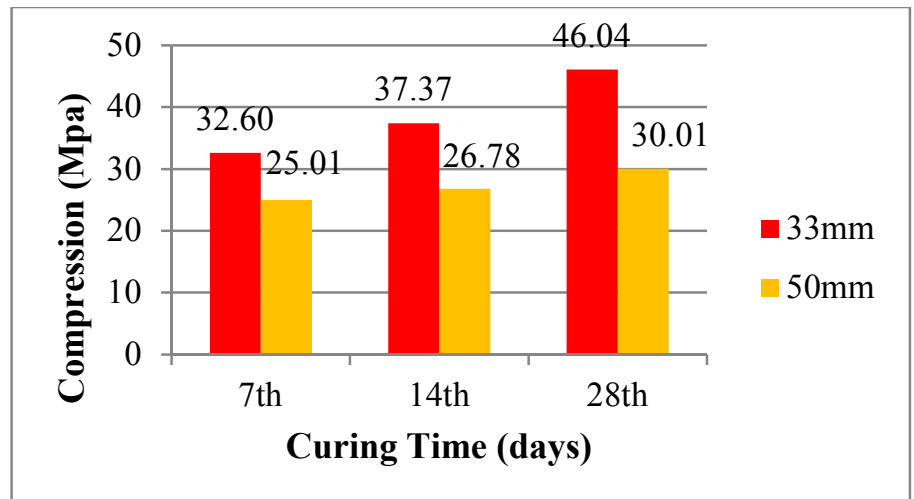

Figure 5 : Compressive strength for $1.0 \%$ of steel fiber.

4.3Compressive strength for $1.5 \%$ of steel fiber.

From $1.5 \%$ of steel fiber, the result is shown in the Figure 6 . The $33 \mathrm{~mm}$ length of steel fiber was also stronger compared to $50 \mathrm{~mm}$ length of steel fiber in term of compressive strength. The higher compressive strength was $35.28 \mathrm{MPa}$ at the $28^{\text {th }}$ days from $33 \mathrm{~mm}$ length of steel fiber. This might be due because the short steel fiber was easy to fill up the void and the concrete was compacted compared with long steel fiber. At the $7^{\text {th }}$ curing, maturity level was weak compared to $28^{\text {th }}$ days curing because at the $28^{\text {th }}$ curing the concrete had reached the level of maturity.Its means the compressive strength was increased when the time of curing were increased. 


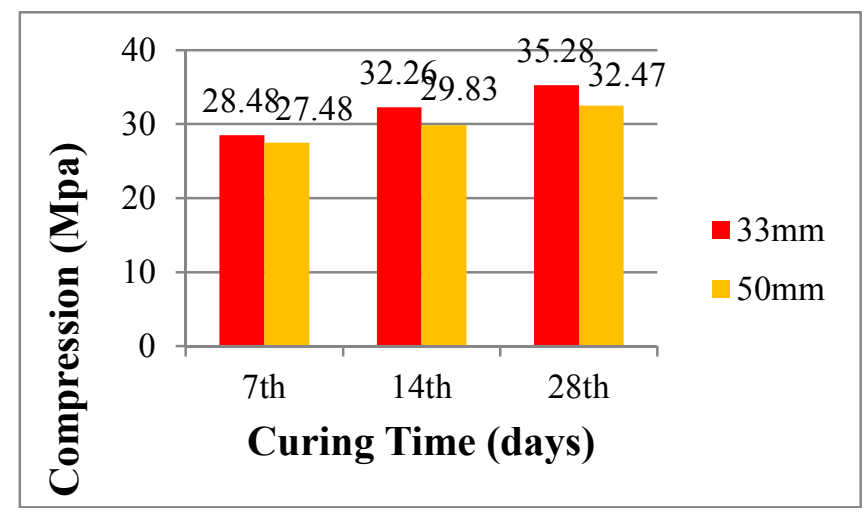

Figure 6 : Compressive strength for $1.5 \%$ of steel fiber.

\section{Conclusion}

For the hardened properties of concrete, the steel fiber can increased the compressive strength. The shorter steel fiber enhanced the compressive strength more than the long steel fiber. Compressive strength were improved when the amount of steel fiber were increased. The maximum volume of steel fiber is $1.0 \%$ which give the higher compressive strength. Meanwhile for the long steel fiber the higher compressive strength was achieved at the $0.5 \%$ of steel fiber. Overall, it can be concluded that by using steel fiber can improve the strength of concrete.. The short steel fiber can improved more compressive strength compared to long steel fiber.

\section{Acknowledgement}

This work was supported by Short Term Grant(U114), UniversitiTunHussienOnn Malaysia and colabration with Civil Engineering Department Universiti Malaysia Perlis

\section{References}

[1] Perumalsamy N. B, Sarendra P. S, "Fiber Reinforced Cement Composites", Mc Graw Hill International Editions 1992.

[2] Xu Z., H. Hao, H.N. Li., 2012. Experiment study of dynamic compressive properties of fiber reinforced concrete material with different fibers. School of Civil and Resource Engineering. University of Western Australia, Crawley, WA 6009, Australia. Material and Design 33, 42-55.

[3] Magnusson J, Hallgern M. Reinforced high strength concrete beams subjected to air blast loading. In: Jones N, Brebbia CA, editors. Structures Under Shock and Impact VIII. WIT Press; 2004.

[4] British Standard 1881 : Part 102 : 1983, Method for determination of slump test.

[5] British Standard : $1191: 1959$, Method for determination the compaction factor test.

[6] British Standard EN 12350-3, 2009, Method for determination the Vebe test.

[7] British Standard 1881 Part 112 : 1983, Method for curing.

[8] MS EN 12390-3:2012, Method for determination the compressive strength. 